\title{
Nasalance and nasality in children with cochlear implants and children with hearing aids
}

\author{
N. Baudonck ${ }^{\mathrm{a}, 1, *}$, K. Van Lierde ${ }^{\mathrm{b}, 1}$, E. D’haeseleer ${ }^{\mathrm{b}}$, I. Dhooge $\mathrm{a}^{\mathrm{a}, \mathrm{c}}$ \\ ${ }^{a}$ Ghent University Hospital, Department of Otorhinolaryngology, Audiology and Logopaedics, and Center for Ambulant Hearing and Speech Rehabilitation \\ "Ter Sprake", de Pintelaan 185, B-9000 Ghent, Belgium \\ ${ }^{\mathrm{b}}$ Ghent University, Department of Speech, Language and Hearing Sciences, de Pintelaan 185, B-9000 Ghent, Belgium \\ ${ }^{\mathrm{c}}$ Ghent University, Department of Otorhinolaryngology, de Pintelaan 185, B-9000 Ghent, Belgium
}

\section{A R T I C L E I N F O}

\section{Article history:}

Received 15 June 2014

Received in revised form 20 January 2015

Accepted 22 January 2015

Available online $\mathrm{xxx}$

\section{Keywords:}

Nasalance

Nasality

Cochlear implants

Hearing aids

Children

\begin{abstract}
A B S T R A C T
Objectives: In prelingually deaf children, many speech production aspects including resonance, are known to be problematic. This study aimed to investigate nasality and nasalance in two groups of prelingually hearing impaired children, namely deaf children with a cochlear implant (CI) and moderateto-severely hearing impaired hearing aid (HA) users. The results of both groups are compared with the results of normal hearing children. Besides, the impact of the degree of hearing loss was determined. Methodology: $36 \mathrm{CI}$ children (mean age: 9;0 y), 25 HA children (mean age: 9;1 y) and $26 \mathrm{NH}$ children (mean age: 9;3 y) were assessed using objective assessment techniques and perceptual evaluations in order to investigate the nasal resonance of the three groups. Ten HA children had thresholds above $70 \mathrm{~dB}$ (range: $91 \mathrm{~dB}-105 \mathrm{~dB}$ ) and fifteen below $70 \mathrm{~dB}$ (range: $58 \mathrm{~dB}-68 \mathrm{~dB}$ ). The Nasometer was used for registration of the nasalance values and nasality was perceptually evaluated by two experienced speech therapists using a nominal rating scale (consensus evaluation).

Results: For nasal stimuli, both $\mathrm{CI}$ children and HA children showed lower nasalance values in comparison with $\mathrm{NH}$ children. The opposite was observed for the oral stimuli. In both hearing impaired groups, cul-de-sac-resonance was observed on a significantly larger scale than in the NH group, and the HA children were judged to be significantly more hypernasal in comparison with $\mathrm{NH}$ children.

Conclusions: Despite the fact that a substantial number of the CI and HA children demonstrate normal (nasal) resonance quality, this aspect of speech production is still at risk for hearing impaired children.

(c) 2015 Elsevier Ireland Ltd. All rights reserved.
\end{abstract}

\section{Introduction}

In prelingually deaf children, many speech production characteristics are known to be problematic. In addition to articulation and voice [1-3], the resonance is often a problem in the speech of prelingually deaf children. Gold [4] even stated that the most frequently mentioned problem of deaf speech is related with nasality. While Wilson [5] described hyponasality as an audible characteristic in the speech of hearing impaired children, many other studies concluded hypernasality as a commonly perceived characteristic [6-11]. Boone [12] described that the hearing impaired patient may demonstrate marked variations in nasal resonance (hyper- and hyponasality) which may be due to the

\footnotetext{
* Corresponding author. Tel.: +32 933244 62; fax: +32 93325436 .

E-mail address: nele.baudonck@uzgent.be (N. Baudonck).

1 The authors N. Baudonck and K. Van Lierde contributed equally to this work.
}

inability to monitor the voice acoustically. Indeed, the 30 profoundly deaf children in the study of Fletcher et al. [10] had significantly higher nasalance values (i.e. the ratio of nasal to nasalplus-oral acoustic energy (\%), as measured with the Nasometer) compared with the normal hearing control group when nasal consonants were absent (reflecting hypernasality) and significantly lower when an utterance was loaded heavily with nasal consonants (reflecting hyponasality). Deviant nasal resonance in prelingually deaf children has been attributed to inefficient control of the velopharyngeal valve as a consequence of absent auditory feedback $[7,10,11]$. Other studies hypothesised that other commonly observed errors in deaf speech, such as a slow speaking rate, articulatory errors and the preference for the neutral vowel may give the impression of hypernasal resonance $[6,7,9]$. Besides this, Boone $[12,13]$ stated that the excessive posterior posturing of the tongue in the hypopharynx lowers the second formant, resulting in a 'cul-de-sac resonance'. 
In the last decennia, cochlear implantation (CI) has become a standard procedure in the rehabilitation of prelingually deaf children. Even though these implants primarily facilitate speech perception, they are also an important aid in the development of several speech production skills, such as overall intelligibility [1416], the production of vowels [2] and consonants [1]. The few studies which focused on resonance characteristics in children using CI [17-21] reported contradictory findings concerning several aspects of nasality or nasalance and conclusions were based on small sample sizes. Monini et al. [17] evaluated nasality in 3 children and 2 adults and concluded a reduction of increased nasality after the activation of the CI. Svirsky et al. [18] also reported an improvement in oral-nasal balance in 5 pediatric $\mathrm{CI}$ users a few minutes after the $\mathrm{CI}$ had been turned on, suggesting that those children used the auditory signal to improve their control of nasalisation. Van Lierde et al. [19] found a statistical difference between the nasalance scores for a nasal reading passage in $9 \mathrm{CI}$ children and $6 \mathrm{HA}$ children, measured by means of a Nasometer. The $\mathrm{CI}$ children had significantly lower nasalance percentages in comparison with the HA children and normative nasalance values [19]. This may reflect hyponasality. However, no differences were measured for the isolated $/ \mathrm{m} /$, oronasal reading passage and perceptual judgements. In the study of Lenden and Flipsen [20] resonance quality remained deviant in the $6 \mathrm{CI}$ children. The majority of the inappropriate utterances were coded as 'nasopharyngeal', more specified as 'cul-de-sac resonance' (i.e. the muffled quality produced by air resonating in a blinded cavity caused by tight anterior constriction or by deep retraction of the tongue into the oral cavity and hypopharynx [22]). Finally, Nguyen et al. [21] also demonstrated a reduction of increased nasalance values following implantation in 6 prelingually deaf children.

Although some studies concluded normalisation of nasality and nasalance after implantation, deviant resonance characteristics, including hyponasality and cul-de-sac resonance, were reported as well. To the best of our knowledge, only the pilot study of Van Lierde et al. [19] has been found that used perceptual (nasality) as well as objective (nasalance) assessment techniques to compare resonance characteristics between $\mathrm{CI}$ children and children using conventional hearing aids (HA). Nonetheless, all conclusions of previous studies were based on small sample sizes. The aim of this study was to determine and compare the objective as well as perceptual resonance quality of a larger sample of $\mathrm{CI}$ children with values of age matched HA users as well as normal hearing $(\mathrm{NH})$ children. Based on previous studies, significant differences between the resonance characteristics of the $\mathrm{CI}$ and HA children with the $\mathrm{NH}$ children were hypothesised. The authors also investigate a possible correlation between (1) the age of implantation ( $\mathrm{CI}$ children) and nasalance, (2) between aided hearing thresholds and nasalance (for $\mathrm{CI}$ and HA children) and between unaided thresholds and nasalance (CI and HA children).

\section{Methods}

This study was approved by the human subject committee of the Universtity of Gent (reference number: 06017).

\subsection{Subjects}

Sixty-one prelingually hearing-impaired children, all enrolled in Flemish oral/aural rehabilitation programs before the age of 3 years, were selected to participate in this study. They all suffered from non-syndromal congenital hearing loss and each child had received a first hearing aid before the age of 3 years. A minimal performal intelligence quotient of 80 and the use of Dutch oral communication mode was required. Thirty-six prelingually deaf children (16 boys and 20 girls, mean age of 9;0 years, range $6 ; 3-11 ; 8$ years) received a multichannel cochlear implant $(\mathrm{CI})$ at the age of $3 ; 4$ years on average (range 6 months-10;9 years). Twenty-five children ( 15 boys and 10 girls, with a mean age of 9;1 years, range 6;8-11.10 years) were bilateral conventional hearing aid (HA) users with a moderate to profound hearing loss. All children had at least one year of experience with their current device ( $\mathrm{HA}$ or $\mathrm{CI}$ ), which was fitted by experienced audiologists. Eight $\mathrm{CI}$ children received a contralateral $\mathrm{CI}$ at a mean age of $4 ; 10$ years (range $2 ; 6-6 ; 3$ years). The HA group consisted of 10 moderately hearing-impaired children with average better ear pure tone thresholds below $70 \mathrm{dBHL}$ ( $\mathrm{HA}<70 \mathrm{dBHL}$; PTA range $58 \mathrm{~dB}-$ $68 \mathrm{~dB}$ ) and 15 severely-to-profoundly hearing-impaired children with thresholds above $70 \mathrm{dBHL}$ (HA $\geq 70 \mathrm{dBHL}$; PTA range: $72 \mathrm{~dB}-$ $105 \mathrm{~dB}), 7$ of whom were profoundly hearing impaired with thresholds above $90 \mathrm{dBHL}$ (PTA range $90 \mathrm{~dB}-105 \mathrm{~dB}$ ). The control group consisted of 26 normal hearing children ( $\mathrm{NH} ; 12$ boys and 14 girls) with a mean age of $9 ; 3$ years (range $6 ; 11-12 ; 0$ years). For the three subgroups, information concerning chronological age, and, where appropriate, age at first hearing aid fitting, most recent better ear unaided hearing threshold (PTA), most recent free field aided hearing threshold and age of implantation is provided in Table 1.

\subsection{Procedures and materials}

\subsubsection{Objective assessment of nasal resonance}

The Nasometer (model 6200; Kay Elemetrics 1994) microcomputer-based system developed by Fletcher and Bishop [23] was used for registration of the nasalance values. The position of the Nasometer headset was adjusted in accordance to the manufacturer's specifications. Each subject was then asked to sustain three vowels (/a/,/i/,/u/), and one consonant $(/ \mathrm{m} /)$ and to read the Dutch reading passages designed by Van de Weijer and Slis [24]. These stimuli are comparable to the type of English passages that are designed specifically for use with the Nasometer. The first passage, an "oronasal" text, contains approximately the same percentage of nasal consonants, $(11.67 \%, 29 / 251)$, found in standard Dutch speech (11.63\%) [25]. The second passage, an "oral" text, excludes nasal consonants and can be used to detect hypernasality. The last passage, a "nasal" text, is loaded with nasal consonants (57\%) and is designed to detect hyponasality in a subject's speech. Children who were not able to read $(29,89 \%, 26 / 87)$, were asked to repeat the text sentence by sentence. In addition, all children were asked to repeat sentences from the SNAP test by MacKay and Kummer [26], which was translated and adapted to Flemish [27]. This test

Table 1

Characteristics of the $\mathrm{CI}, \mathrm{HA}$ and $\mathrm{NH}$ groups.

\begin{tabular}{|c|c|c|c|c|c|}
\hline & $\begin{array}{l}\text { Chronological } \\
\text { age (years) }\end{array}$ & $\begin{array}{l}\text { Age at first HA } \\
\text { (months) }\end{array}$ & $\begin{array}{l}\text { Better ear hearing } \\
\text { threshold unaided (dBHL) }\end{array}$ & $\begin{array}{l}\text { Free field aided } \\
\text { hearing threshold (dBHL) }\end{array}$ & Age at implantation (years) \\
\hline & Mean (SD) & Mean (SD) & Mean (SD) & Mean (SD) & Mean (SD) \\
\hline NH group $(n=26)$ & $9 ; 3(1 ; 9)$ & - & - & - & - \\
\hline HA group $(n=25)$ & $9 ; 1(1 ; 7)$ & $13(10)$ & $78(16)$ & $36(7)$ & - \\
\hline CI group $(n=36)$ & $9 ; 0(1 ; 9)$ & $12(9)$ & $108(12)$ & $34(8)$ & $3 ; 4(2 ; 11)$ \\
\hline
\end{tabular}

$\mathrm{NH}=$ normal hearing; $\mathrm{CI}=$ cochlear implant; $\mathrm{HA}=$ hearing aid; $\mathrm{SD}=$ standard deviation. 
included 5 passages focusing, respectively on bilabials, alveolars, velars, sibilants and nasals. Each subject was asked to repeat or read the text or SNAP sentences once. If the subjects made an error, they were asked to repeat the stimulus again.

\subsubsection{Subjective assessment of nasal resonance}

In addition, speech samples of connected speech during reading were audio-recorded (laptop, Toshiba M70 with Harman/Kardon sound card and acoustic amplifier Monacor MKA-60SET/WS) for further perceptual judgement. For evaluating the degree of, perceived overall resonance quality, hypernasality, hyponasality, cul-de-sac-resonance and nasal emissions (abnormal flow of air from the nares during the production of high-pressure consonants), a nominal scale containing 4 categories was used $(0=$ normal nasalance, 1 = mild, 2 = moderate, 3 = severe impairment). First, a random number was attributed to each child of the three subgroups using the online available random integer generator (www.random. org). The randomly sorted speech samples were first rated, indepently, by two experienced speech therapists (NB, ED). Concordance values were $83.33 \%$. By lack of agreement, the samples were replayed until a consensus was reached.

\subsection{Statistics}

SPSS for Windows (version 15.0) was used for the statistical analysis. The results for the $\mathrm{CI}$ children were compared with the results for the HA-children, $\mathrm{HA}<70 \mathrm{dBHL}$-children, $\mathrm{HA} \geq 70 \mathrm{dBHL}-\mathrm{children}$ and $\mathrm{NH}$ children. The Kolmogorov-Smirnov test $(\alpha=0.01)$ and the Shapiro Wilk test were performed to study the distribution of the variables. In case of normal distribution, a 'One-way ANOVA' in combination with a post hoc Scheffe was applied. When a deviation from a normal distribution occured, Kruskal-Wallis tests were executed to document possible differences between the three subgroups. When the obtained $p$-value was smaller than 0.05 , pair wise comparisons were executed using a Mann-Whitney procedure. For the comparison of the perceptual judgments of the resonance quality, the Chi square test was applied. The Spearman's correlation coefficient was computed to look for a correlation between (1) the age of implantation (CI children) and nasalance, (2) between aided hearing thresholds and nasalance (for $\mathrm{CI}$ and HA children) and between unaided thresholds and nasalance ( $\mathrm{CI}$ and HA children).

\section{Results}

\subsection{Descriptives}

A Mann-Whitney $U$ test showed that mean chronological age, duration of initial hearing loss and mean performal intelligence quotient of the $\mathrm{CI}$ and $\mathrm{HA}$ group, $\mathrm{HA}<70 \mathrm{dBHL}$ group and $\mathrm{HA} \geq 70 \mathrm{dBHL}$ group did not differ significantly $(p>0.05)$. With regards to audiometric data, recent better ear unaided thresholds were significantly better in both HA groups $(p<0.001)$ compared to the CI group, while the aided thresholds in free field condition showed no marked difference.

\subsection{Nasalance values}

Concerning nasalance differences between the NH subgroup and both, the CI and HA group were significant for the isolated consonant/m/and the SNAP sentences containing alveolar consonants $(p<0.05)$. For the oral reading text, only the HA group demonstrated a significant difference with the NH group $(p<0.05)$ and the difference between the $\mathrm{CI}$ and $\mathrm{NH}$ group was not significant $(p=0.07)$. For the nasal reading text, only de CI group demonstrated a significant difference with the $\mathrm{NH}$ group and the
HA group showed no difference with the NH group ( $p=0.07$ ). There was a clear tendency for nasal stimuli in $\mathrm{CI}$ children as well as HA children to have lower nasalance values compared to NH children, while for the oral stimuli, the opposite was observed. No significant differences were found between $\mathrm{CI}$ and HA children. All results are presented in Fig. 1.

When dividing the HA group in a moderately hearing impaired $\mathrm{HA}<70 \mathrm{dBHL}$ subgroup and a severely hearing impaired $\mathrm{HA} \geq 70 \mathrm{dBHL}$ subgroup, no differences were found between the $\mathrm{CI}$ and both HA subgroups. The $\mathrm{HA}<70 \mathrm{dBHL}$ subgroup only showed one significant difference with the $\mathrm{NH}$ group, namely a lower nasalance value for the isolated $/ \mathrm{m} /$.

Finally, correlations between the age at implantation (CI children) and nasalance scores could not be found, nor between aided or unaided thresholds ( $\mathrm{CI}$ and HA children) and nasalance scores (see Table 2).

\subsection{Consensus perceptual evaluation}

The overall resonance quality of the $\mathrm{HA} \geq 70 \mathrm{dBHL}$ group was judged to be the most deviant, followed by the CI group, the $\mathrm{HA}<70 \mathrm{dBHL}$ group and finally the $\mathrm{NH}$ group (Fig. 2). The differences between the subgroups was significant $(p<0.001)$ except for the difference between the $\mathrm{HA}<70 \mathrm{dBHL}$ group and the $\mathrm{NH}$ group. No other differences were observed between the $\mathrm{CI}$ and HA subgroups. In Fig. 2 one can see that, compared to NH children, hypernasality was observed on a significantly larger scale in $\mathrm{HA} \geq 70 \mathrm{dBHL}$ children. This was not the case for $\mathrm{CI}$ children or $\mathrm{HA}<70 \mathrm{dBHL}$. In the $\mathrm{CI}$ and in both, the $\mathrm{HA} \geq 70 \mathrm{dBHL}$ and $\mathrm{HA}<70 \mathrm{dBHLgroup}$, the presence of cul-de-sac-resonance was observed on a significantly larger scale than in the NH group, as seen in Fig 2. Finally, nasal emissions were observed in three HA children and $1 \mathrm{CI}$ child (age at CI: 9;6 y).

\section{Discussion}

Few investigators reported the resonance characteristics in children using a CI. The studies [17-21] mentioned contradictory findings concerning several aspects of nasality or nasalance and conclusions were based on small sample sizes $(n<10)$. The present study aimed to investigate nasalance and nasality in $36 \mathrm{CI}$ children and 25 hearing aid users (10 of whom were moderately hearing-impaired and 15 severely hearing-impaired). Subjective as well as objective assessment methods were used. Finally, the authors tried to investigate a correlation between (1) the age of implantation (CI children) and nasalance, (2) between aided hearing thresholds and nasalance (for $\mathrm{CI}$ and HA children) and between unaided thresholds and nasalance (CI and HA children).

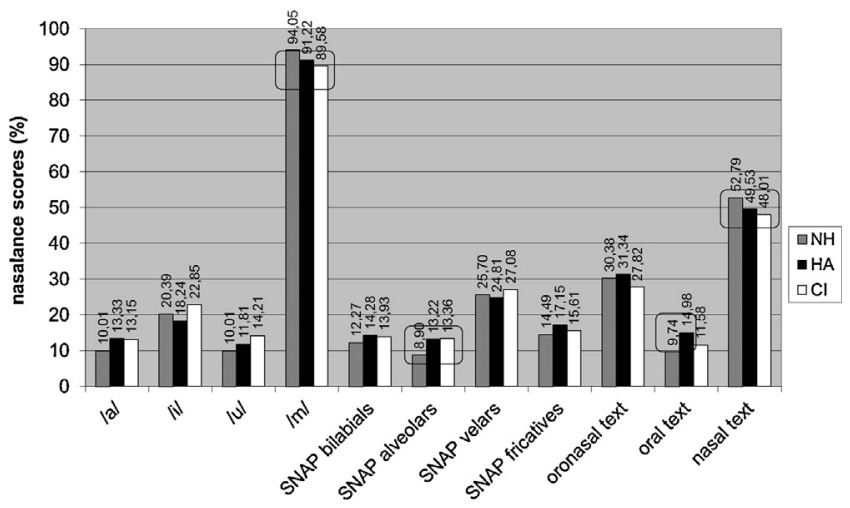

Fig. 1. Nasalance-scores in CI-HA- and NH-children: sunificant differnces are indicated by the circles. 
Table 2

Correlations.

\begin{tabular}{|c|c|c|c|}
\hline Correlation & Age at CI & $\begin{array}{l}\text { Unaided } \\
\text { threshold } \\
\text { (better ear) }\end{array}$ & $\begin{array}{l}\text { Aided } \\
\text { threshold better } \\
\text { ear (HA or } \mathrm{CI})\end{array}$ \\
\hline$|a|$ & $\begin{array}{l}r_{s}: 0.144 \\
\text { sig. } 0.409\end{array}$ & $\begin{array}{l}r_{s}: 0.145 \\
\text { sig. } 0.300\end{array}$ & $\begin{array}{l}r_{s}: 0.041 \\
\text { sig. } 0.769\end{array}$ \\
\hline /i/ & $\begin{array}{l}r_{s}: 0.187 \\
\text { sig.0.281 }\end{array}$ & $\begin{array}{l}r_{s}: 0.258 \\
\text { sig.0.062 }\end{array}$ & $\begin{array}{l}r_{s}:-0.062 \\
\text { sig.0.655 }\end{array}$ \\
\hline $\mid \mathrm{u} /$ & $\begin{array}{l}r_{s}: 0.125 \\
\text { sig.0.476 }\end{array}$ & $\begin{array}{l}r_{s}: 0.232 \\
\text { sig.0.094 }\end{array}$ & $\begin{array}{l}r_{s}:-0.187 \\
\text { sig.0.175 }\end{array}$ \\
\hline$/ \mathrm{m} /$ & $\begin{array}{l}r_{s}: 0.272 \\
\text { sig.0.114 }\end{array}$ & $\begin{array}{l}r_{s}:-0.131 \\
\text { sig.0.329 }\end{array}$ & $\begin{array}{l}r_{s}: 0.012 \\
\text { sig.0.929 }\end{array}$ \\
\hline SNAP bilabials & $\begin{array}{l}r_{s}: 0.091 \\
\text { sig.0.619 }\end{array}$ & $\begin{array}{l}r_{s}: 0.174 \\
\text { sig.0.236 }\end{array}$ & $\begin{array}{l}r_{s}: 0.171 \\
\text { sig.0.241 }\end{array}$ \\
\hline SNAP alveolars & $\begin{array}{l}r_{s}: 0.031 \\
\text { sig.0.865 }\end{array}$ & $\begin{array}{l}r_{s}: 0.152 \\
\text { sig.0.308 }\end{array}$ & $\begin{array}{l}r_{s}: 0.010 \\
\text { sig.0.947 }\end{array}$ \\
\hline SNAP velars & $\begin{array}{l}r_{s}: 0.050 \\
\text { sig.0.785 }\end{array}$ & $\begin{array}{l}r_{s}: 0.258 \\
\text { sig.0.077 }\end{array}$ & $\begin{array}{l}r_{s}: 0.115 \\
\text { sig.0.431 }\end{array}$ \\
\hline SNAP fricatives & $\begin{array}{l}r_{s}: 0.049 \\
\text { sig.0.789 }\end{array}$ & $\begin{array}{l}r_{s}: 0.008 \\
\text { sig.0.955 }\end{array}$ & $\begin{array}{l}r_{s}:-0.070 \\
\text { sig.0.633 }\end{array}$ \\
\hline SNAP nasals & $\begin{array}{l}r_{s}: 0.171 \\
\text { sig.0.350 }\end{array}$ & $\begin{array}{l}r_{s}: 0.056 \\
\text { sig.0.704 }\end{array}$ & $\begin{array}{l}r_{s}:-0.032 \\
\text { sig.0.826 }\end{array}$ \\
\hline Oronasal text & $\begin{array}{l}r_{s}: 0.221 \\
\text { sig. } 0.240\end{array}$ & $\begin{array}{l}r_{s}: 0.013 \\
\text { sig.0.930 }\end{array}$ & $\begin{array}{l}r_{s}: 0.018 \\
\text { sig.0.904 }\end{array}$ \\
\hline Oral text & $\begin{array}{l}r_{s}:-0.212 \\
\text { sig. } 0.260\end{array}$ & $\begin{array}{l}r_{s}: 0.044 \\
\text { sig.0.769 }\end{array}$ & $\begin{array}{l}r_{s}: 0.079 \\
\text { sig.0.598 }\end{array}$ \\
\hline Nasal text & $\begin{array}{l}r_{s}: 0.136 \\
\text { sig.0.482 }\end{array}$ & $\begin{array}{l}r_{s}: 0.058 \\
\text { sig.0.707 }\end{array}$ & $\begin{array}{l}r_{s}:-0.069 \\
\text { sig.0.650 }\end{array}$ \\
\hline
\end{tabular}

$r_{s}=$ Spearman's correlation coefficient, sig. = significance value.

The HA-children and the CI-children in this study demonstrate several significant differences for nasal resonance compared with the $\mathrm{NH}$ control group for the objective assessments (nasalance) and the subjective judgements (nasality). Generally, the overall resonance quality of the $\mathrm{HA} \geq 70 \mathrm{dBHL}$ group was judged to be disturbed more seriously compared to the $\mathrm{CI}$ group. The judges described more $\mathrm{HA} \geq 70 \mathrm{dBHL}$ children as slightly-to-severely hypernasal compared to the $\mathrm{NH}$ children. Indeed, the mean score for the oral reading text was also significantly increased compared to the $\mathrm{NH}$ group, reflecting the presence of hypernasality in $\mathrm{HA} \geq 70 \mathrm{dBHL}$ children. This was not the case for the $\mathrm{CI}$ children. In that respect, this result agrees with the results of Monini et al. [17] who reported a normalisation of the increased nasality after implantation. However, the CI children still showed increased nasalance scores for the SNAP sentences with alveolars; this was also the case for the HA $\geq 70 \mathrm{dBHL}$. On the other hand, for some nasal stimuli decreased nasalance scores were found in the hearing impaired groups compared to the $\mathrm{NH}$ group; for example the production of a sustained $/ \mathrm{m} /$, and for the CI group, the nasal reading text. Those alternating hypo- and hypernasal results may demonstrate the absence of adequate control of the nasal-oral balance in severely hearing impaired children with $\mathrm{CI}$ or HA. This phenomenon was already described by Boone [12] and Fletcher [10] in prelingually deaf children without $\mathrm{CI}$, and now also applies to $\mathrm{CI}$ children, regarding the results of the present study. This means that moderate-to-profoundly hearing impaired children, including $\mathrm{CI}$ children, show inappropriate coordination of the velopharyngeal function due to the inadequate auditory feedback. Finally, compared to the NH group, the resonance of more HA and $\mathrm{CI}$ children was described as a slight to severe 'cul-de-sacresonance'. Boone [13] already used this term to describe the resonance of prelingually deaf children. More recently, in the study of Lenden and Flipsen [20], the majority of the inappropriate utterances of $6 \mathrm{CI}$ children were coded as 'nasopharyngeal' which included 'cul-de-sac resonance'.

It is obvious that HA children, and also $\mathrm{CI}$ children are at risk of nasal resonance abnormalities such as an inadequate control of the oral-nasal balance, cul-de-sac-resonance and, in some cases, also nasal emissions. On the other hand, a substantial number of hearing impaired children demonstrate normal resonance and nasality. Regarding the perceptual judgements, the overall resonance of the HA children was found to be more aberrant than in the CI group. Moreover, hypernasality was more severe in the HA group, as demonstrated by the higher nasalance scores for the oral texts as well as the perceptual judgements. These findings suggest an improvement in oral-nasal balance for $\mathrm{Cl}$ children. Svirsky et al. [18] described two hypothesis for the underlying reasons for the normalisation of nasalance values after implantation. The most simple 'feedback' hypothesis is that deaf children use their enhanced auditory feedback to improve their nasalance control: due to the $\mathrm{CI}$, deaf children may be able to detect discrepancies between intended and actual acoustic correlates of nasalance. The more complicated 'indirect' hypothesis is that the improved nasalance is an indirect consequence of changes in other speech production parameters. Indeed, previous studies of Baudonck et al. [1-3] describe improved speech production characteristics in $\mathrm{CI}$ children compared to HA children. The consonant production of implanted children is more adequate than the consonant production of $\mathrm{HA} \geq 70 \mathrm{dBHL}$ children, the voices of the $\mathrm{CI}$ children are perceptually judged to be better compared to $\mathrm{HA} \geq 70 \mathrm{dBHL}$ and HA children show the tendency to a more dorsal articulation of the vowels, which was not seen in the $\mathrm{CI}$ children.

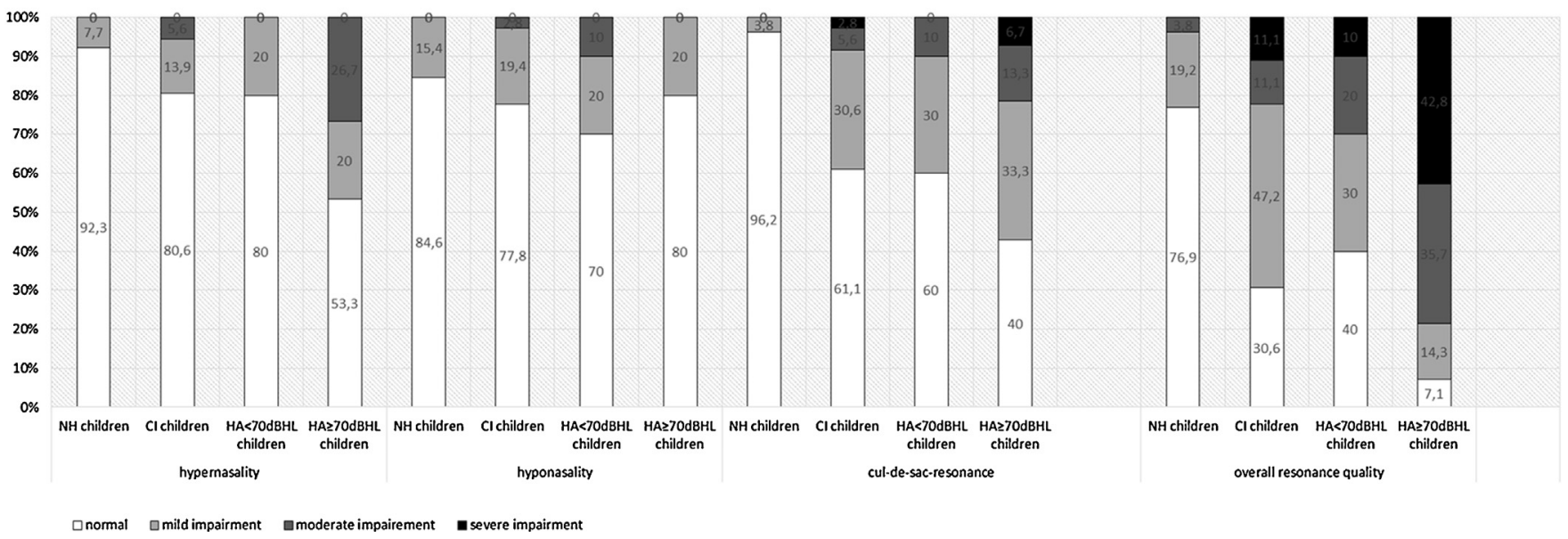

Fig. 2. Number of children taht received a certain score for the perceptual evaluation. 
Despite the fact that a substantial number of the $\mathrm{CI}$ - and the $\mathrm{HA}$ children demonstrate normal resonance quality, nasalance and nasality, those aspects of speech production are still a risk for hearing impaired children. To what extent the remaining resonance deviations are related to the age of rehabilitation and implantation, or other variables, is subject to further research. In this study, no correlation can be found between hearing thresholds (aided or unaided) and nasalance scores. Despite the fact that the average unaided hearing threshold is significantly higher in the $\mathrm{CI}$ group (severe to profound hearing loss is a condition for cochlear implantation), nasalance scores of the $\mathrm{CI}$ group is at least as well as the scores in the HA group and for some aspects even better. Aided thresholds are not different between both groups. It would be interesting to repeat nasalance measures in a major group HA children with a mild to severe hearing loss and to investigate were the measures of $\mathrm{CI}$ children are situated. In this study, also no correlation between age at implantation and nasalance scores can be found. In that context it is worth mentioning that the majority of the $\mathrm{CI}$ children are implanted very early (17 children were implanted before the age of 2 yrs) and that only 8 children were implanted after the age of 5 . Above, all children are enrolled in intensive rehabilitation programs in which speech therapy is an important aspect. Above, also in prelingually deaf adults who are implanted during adulthood (early deafened late implanted) a change in nasalance toward the norm is demonstrated [28]. To investigate correlation between age at implantation and nasalance, a major group of $\mathrm{CI}$ children and adults with different ages of implantation is required.

De Bodt et al. [29] concluded that resonance, in addition to voice, prosody and, in particular, articulation can influence the intelligibility in dysartric speech. As the above described resonance deviations are rather mild in most of the cases, it is necessary to explore further whether they will have a harmful effect on the overall speech intelligibility of hearing impaired children. Possibly, they will have an impact on the naturalness, as opposed to the intelligibility of speech. Audible deviations from the standard pronunciation do not necessarily interfere with the correct identification (intelligibility); for instance, the degree of finegrained variations in synthesised speech is linked to both intelligibility and naturalness ratings [30]. The above mentioned nasalance and nasality abnormalities are possible examples of such fine-grained variations involving naturalness. Speech naturalness is a term defined by the listeners' perspective as speech that "sounds normal or natural" [31] and is measured, by preference, by means of perceptual rating scales. When it comes to speech production in early rehabilitated hearing impaired children, future research should pay more attention to speech naturalness in addition to intelligibility [16].

In summary, despite the fact that a substantial number of the $\mathrm{CI}$ - and the HA children demonstrate normal resonance quality, nasalance and nasality, those aspects of speech production are still a risk for hearing impaired children. In the context of speech intelligibility and, more importantly, speech naturalness, further investigation into those aspects is needed.

\section{References}

[1] N. Baudonck, I. Dhooge, E. D'haeseleer, K. Van Lierde, A comparison of consonant productions between children using cochlear implants or hearing aids, Int. J. Pediatr. Otorinolaryngol. 74 (2010) 416-421.
[2] N. Baudonck, I. Dhooge, K. Van Lierde, P. Corthals, A comparison of vowel productions in prelingually deaf children using cochlear implants severely hearing impaired children using conventional hearing aids and normal hearing children, Folia Phoniatr. Logop. 63 (2011) 154-160.

[3] N. Baudonck, E. D'haeseleer, I. Dhooge, K. Van Lierde, Objective vocal quality in children using cochlear implants: a multiparameter approach, J. Voice 25 (2011) 683-691.

[4] T. Gold, Speech production in hearing impaired children, J. Commun. Disord. 13 (1980) 397-418.

[5] B.S. Wilson, C.C. Finley, D.T. Lawson, R.D. Wolford, D.K. Eddignton, W.M. Rabinowitz, Better speech recognition with cochlear implants, Nature 352 (1991) 236-238.

[6] R. Colton, H. Cooker, Perceived nasality in the speech of the deaf, J. Speech Hear. Res. 11 (1968) 553-559.

[7] K. Stevens, R. Nickerson, A. Boothroyd, A. Rollins, Assessment of nasalization in the speech of deaf children, J. Speech Lang. Hear. Res. 19 (1976) 393-416.

[8] S.G. Fletcher, D.A. Daly, Nasalance in utterances of hearing-impaired speakers, J. Commun. Disord. 9 (1976) 63-73.

[9] S.G. Fletcher, J.M. Higgins, Performance of children with severe to profound auditory impairment in instrumentally guided reduction of nasal resonance, J. Speech. Hear. Disord. 45 (1980) 181-194.

[10] S.G. Fletcher, F. Mahfuz, H.H. Hendarmin, Nasalance in the speech of children with normal hearing and children with hearing loss, Am. J. Speech-Lang. Pathol. 8 (1999) 241-248.

[11] P.R. Lapine, M.G. Stewart, J. Tatchell, Application of nasometry to speech samples of hearing-impaired children, Percept. Motor Skills 73 (1991) 467-475.

[12] D.R. Boone, S.C. McFarlane, The Voice and Voice Therapy, Prentice-Hall, New Jersey, 1971.

[13] D.R. Boone, Modification of the voices of deaf children, Volta Rev. 68 (1966) 686-692.

[14] A.S. Uziel, A. Sillon, A. Vieu, F. Artieres, J.-P. Piron, J.P. Daures, et al., Ten years follow-up of a consecutive series of children with multichannel cochlear implants, Otol. Neurotol. 28 (2007) 615-628.

[15] M. Bakhshaee, M.M. Ghasemi, M.T. Shakeri, N. Razmara, H. Tayarani, M.R. Tale, Speech development in children after cochlear implantation, Eur. Arch. Otorhinolaryngol. 264 (2007) 1263-1266.

[16] N. Baudonck, I. Dhooge, K. Van Lierde, Intelligibility of hearing impaired children as judged by their parents: a comparison between children using cochlear implants and children using hearing aids, Int. J. Pediatr. Otorinolaryngol. 74 (2010) 1310-1350

[17] S. Monini, G. Banci, M. Barbara, M.T. Argiro, R. Filipo, Clarion cochlear implant: short-term effects on voice parameters, Am. J. Otol. 18 (1997) 719-725.

[18] M.A. Svirsky, D. Jones, M.J. Osberger, R.T. Miyamoto, The effect of auditory feedback on the control of oral-nasal balance by pediatric cochlear implant users, Ear Hear. 19 (1998) 385-393.

[19] K.M. Van Lierde, B.M. Vinck, N. Baudonck, E. De Vel, I. Dhooge, Comparison of the overall intelligibility, articulation, resonance, and voice characteristics between children using cochlear implants and those using bilateral hearing aids: a pilot study, Int. J. Audiol. 8 (2005) 452-465

[20] J.M. Lenden, P. Flipsen, Prosody and voice characteristics of children with cochlear implants, J. Commun. Disord. 40 (2007) 66-81.

[21] L.H. Nguyen, J. Allegro, A. Low, B. Papsin, P. Campisi, Effect of cochlear implantation on nasality in children, Ear Nose Throat J. 87 (2008) 140-143.

[22] S.J. Peterson-Falzone, Speech disorders related to craniofacial structural defects, part 2, in: N.J. Lass, L.V. McReynolds, J.L. Northern, D.E. Yoder (Eds.), Handbook of Speech-Language Pathology and Audiology, B.C. Decker, Toronto, 1988.

[23] S. Fletcher, M. Bishop, Measurement of nasality with TONAR, Cleft Palate J. 10 (1973) 610-621.

[24] J.C. Van de Weijer, I.H. Slis, Nasaliteitsmeting met de nasometer, Logopedie Foniatrie 63 (1991) 97-101.

[25] M. Van den Broecke, S. Ruijters, S. Van der Meulen, Verschillen in moeilijkheidsgraad in distinctieve kenmerken bij consonanten en consonant clusters, Logopdie Foniatrie 56 (1984) 2-9.

[26] I.R.A. MacKay, A.W. Kummer, The MacKay Kummer SNAP Test, New Jersey, Kay Elemetrics Corp., 1994.

[27] K. Van Lierde, F. Wuyts, M.D. De Bodt, P. Van Cauwenberge, Age-related patterns of nasal resonance in normal Flemish children and young adults, Scan. J. Plast. Reconstruct. Surg. Hand Surg. 6 (2003) 344-350.

[28] M.K. Evans, D.D. Deliyski, Acoustic voice analysis of prelingually deaf adults before and after cochlear implantation, J. Voice 21 (2007) 669-682.

[29] M.S. De Bodt, M.E. Hernandez-Diaz, P. Huici, P. Van de Heyning, Intelligibility as a linear combination of dimensions in dysarthric speech, J. Commun. Disord. 35 (2002) 283-292.

[30] J. Wouters, M.W. Macon, Effects of prosodic factors on spectral dynamics II. Synthesis, J. Acoust. Soc. Am. 111 (2002) 428-438

[31] S. Coughlin-Woods, M.E. Lehman, P.A. Cooke, Ratings of speech naturalness of children ages 8-16 years, Percept. Motor Skills 100 (2005) 295-304. 